\title{
An In Vitro Study to Compare the Surface Roughness of Two Polyvinylsiloxane Impression Materials Following Ultraviolet Irradiation or Chemical Disinfection
}

\author{
Ruksana Farooqui ${ }^{1}$, Meena A Aras ${ }^{2}$, Vidya Chitre ${ }^{3}$
}

\begin{abstract}
Aim and objective: To evaluate and compare the surface roughness of two polyvinylsiloxane impression materials following ultraviolet irradiation and chemical disinfection.

Materials and methods: The surface roughness of two different polyvinylsiloxane impression materials (Elite HD+ and Aquasil) were evaluated following ultraviolet irradiation and chemical disinfection using a surface profilometer. Sixty specimens of each impression material were fabricated and divided into one control two experimental groups. The mean surface roughness values among the treatment groups were recorded and subjected to the statistical analysis.

Results: Both the materials showed a statistically significant increase in the surface roughness values following ultraviolet irradiation and chemical disinfection. In general, the control groups presented the least surface roughness and the chemical groups presented the maximum surface roughness values.

Conclusion: Ultraviolet irradiation sterilization of polyvinylsiloxane elastomeric impression materials resulted in a lower surface roughness and hence may be preferred over chemical disinfection.

Keywords: Chemical disinfection, Polyvinylsiloxane impression materials, Surface roughness, Ultraviolet irradiation.

International Journal of Experimental Dental Science (2020): 10.5005/jp-journals-10029-1215
\end{abstract}

\section{INTRODUCTION}

Impression materials in dentistry are used to register the form and relation of the teeth and the surrounding oral tissues. To prevent the possible spread of infectious diseases like HIV AIDS, Hepatitis $B$, etc., the American Dental Association (ADA) and the Centers for Disease Control (CDC) have recommended disinfection of dental impressions. ${ }^{1,2} \mathrm{~A}$ number of physical and chemical methods have been proposed for the disinfection of dental impressions. Physical action yields an increase in temperature, which may result in distortion of impression materials, and hence chemical disinfection is believed to be the simplest and an effective form of infection control. As per the ADA guidelines, the impression must be rinsed thoroughly to remove saliva, blood, and debris. This is followed by immersion in a disinfecting agent like glutaraldehyde, iodophor, or hypochlorite. ${ }^{3}$

Certain microbial forms, for instance, bacterial spores, are not eliminated by chemical disinfection alone. Hence, alternative methods have been introduced such as steam autoclave, microwave, ethylene oxide gas autoclave, gaseous ozone, and radiofrequency glow discharging. ${ }^{4,5}$ In recent years, ultraviolet (UV) radiation has become an effective way of disinfecting impressions as they are effective in destroying the microorganisms and the bacterial spores while preserving the quality of the material. ${ }^{6}$

The SARS-CoV-2 virus that has caused outbreaks globally has not yet been specifically evaluated for its vulnerability to ultraviolet irradiation. However, several studies on related coronaviruses, as well as the SARS coronavirus, have shown that they are greatly susceptible to ultraviolet radiation inactivation. ${ }^{7}$ An accurate impression of the dental tissues is a major requirement for the precise adaptation of the dental prosthesis. Polyvinylsiloxane

\footnotetext{
${ }^{1-3}$ Department of Prosthodontics and Crown and Bridge, Goa Dental College and Hospital, Bambolim, Goa, India

Corresponding Author: Ruksana Farooqui, Department of Prosthodontics and Crown and Bridge, Goa Dental College and Hospital, Bambolim, Goa, India, Phone: +91 7218282688, e-mail: farooquiruksana@gmail.com

How to cite this article: Farooqui R, Aras MA, Chitre V. An In Vitro Study to Compare the Surface Roughness of Two Polyvinylsiloxane Impression Materials Following Ultraviolet Irradiation or Chemical Disinfection. Int J Experiment Dent Sci 2020;9(2):52-55.

Source of support: Nil

Conflict of interest: None
}

elastomeric impression materials have excellent physical and mechanical properties and hence are the materials of choice for all impression procedures in dentistry. ${ }^{5}$

An impression with irregularities or surface defects may result in an ill-fitting prosthesis. In order to prevent plaque and calculus buildup and also improve esthetics, a smooth intaglio surface is desirable. Any irregularities on the intaglio surface of the prosthesis might influence its fit. Such irregularities may result from alterations in the material's properties following disinfection procedures. ${ }^{8,9}$

The rationale of this study was to assess the outcome of chemical disinfection and ultraviolet irradiation on the surface roughness of two different polyvinylsiloxane elastomeric impression materials. The null hypothesis was that ultraviolet irradiation and chemical disinfection do not have any effect on the surface roughness of polyvinylsiloxane elastomeric impression materials.

(c) The Author(s). 2020 Open Access This article is distributed under the terms of the Creative Commons Attribution 4.0 International License (https:// creativecommons.org/licenses/by-nc/4.0/), which permits unrestricted use, distribution, and non-commercial reproduction in any medium, provided you give appropriate credit to the original author(s) and the source, provide a link to the Creative Commons license, and indicate if changes were made. The Creative Commons Public Domain Dedication waiver (http://creativecommons.org/publicdomain/zero/1.0/) applies to the data made available in this article, unless otherwise stated. 




Fig. 1: Metal matrix with impression material

\section{Materials and Methods Materials Used}

Polyvinylsiloxane; light body (Aquasil Dentsply, Germany) Polyvinylsiloxane; light body (Elite HD+, Zhermack)

Stainless steel metal matrix

2\% glutaraldehyde (CIDEX Johnson \& Johnson company)

\section{Equipment}

Ultraviolet chamber (Thermo Electric Technologies, Bengaluru, India)

Surface profilometer (Bruker Contour GT-K; Bruker Nano, Berlin, Germany)

\section{Method}

A rectangular stainless steel metal plate with 15 cylindrical matrices (dimension $2 \mathrm{~mm}$ in thickness and $20 \mathrm{~mm}$ diameter) was used to fabricate the specimens. Two glass slabs one on the top and one below of the rectangular stainless steel plate were used (Fig. 1). This resulted in a standardized size of the test specimens and to retrieve them without deformation. A total of 120 specimens were fabricated with 60 specimens for each of the two polyvinylsiloxane impression materials used.

The base and accelerator pastes of each polyvinylsiloxane impression materials were dispensed and hand mixed as per the manufacturers' instructions. The mixed material was then placed in the matrices and smoothened using a spatula to standardize the thickness. The specimens were allowed to set in a thermostatically controlled water bath at $37^{\circ} \mathrm{C}$. Following setting of the material, the specimens were carefully retrieved and stored at room temperature in zip-lock plastic bags.

The specimens were divided as follows:

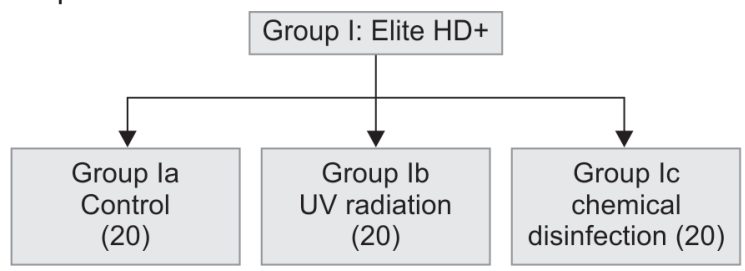

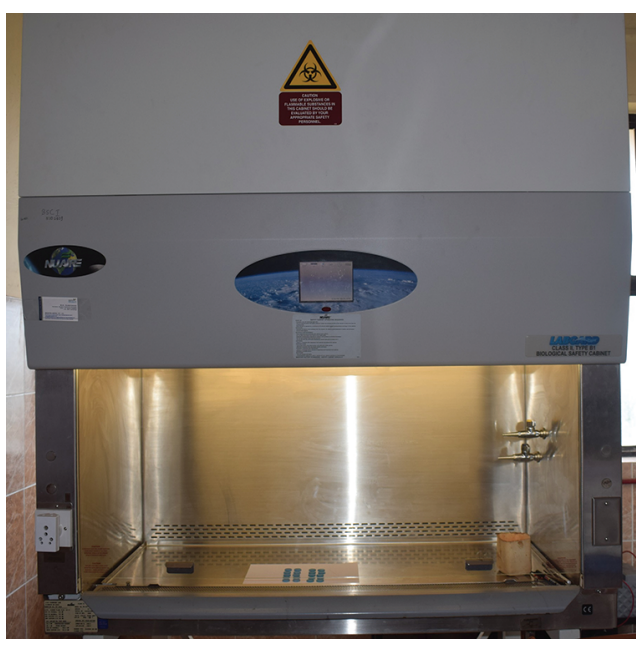

Fig. 2: Specimens placed in an ultraviolet chamber

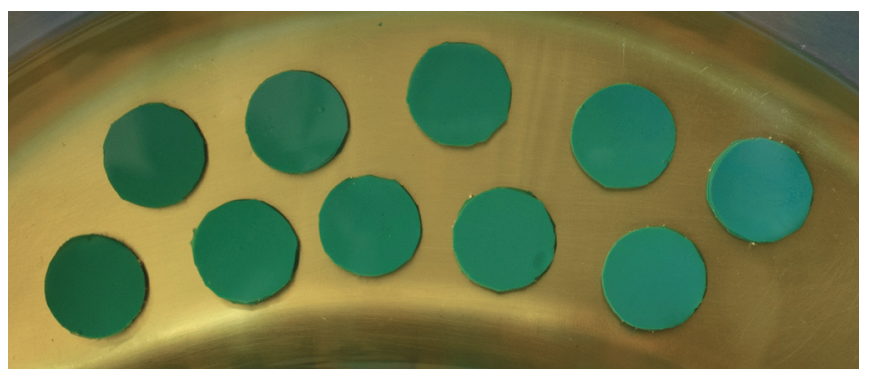

Fig. 3: Specimens immersed in $2 \%$ glutaraldehyde

Group la and Ila (control): No sterilization was used.

Group Ib and Ilb (UV radiation): Specimens were placed in an ultraviolet chamber for 10 minutes (Fig. 2).

Group Ic and IIc (chemical disinfection): Specimens were immersed in $2 \%$ glutaraldehyde for 10 minutes as per manufacturer's recommendations (Fig. 3).

\section{Measurement of Surface Roughness}

The surface roughness was measured at five randomly selected areas in each sample using a noncontacting optical surface profilometer (Bruker Contour GT-K; Bruker Nano, Berlin, Germany) and average value was recorded.

\section{Results}

One-way ANOVA was carried out to compare the mean surface roughness among the different subgroups in group I (Elite $\mathrm{HD}^{+}$) and group II (Aquasil), respectively (Table 1). The surface roughness was found to be the highest in group Ic (0.540) and the lowest in group Ila (0.26745). The Tukey HSD test revealed that the difference

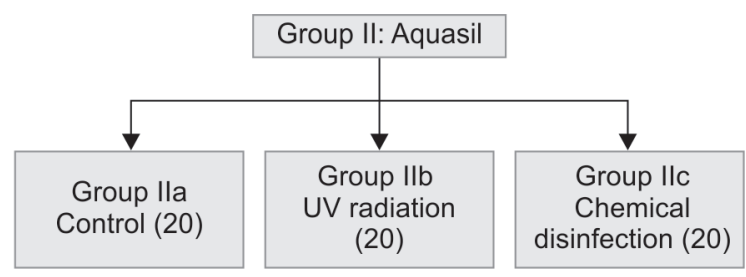


Table 1: Descriptive statistics for the surface roughness for different groups

\begin{tabular}{|c|c|c|c|c|c|c|c|c|}
\hline \multirow{2}{*}{\multicolumn{2}{|c|}{ Materials }} & \multirow[b]{2}{*}{$N$} & \multirow[b]{2}{*}{ Mean } & \multirow[b]{2}{*}{ Std. deviation } & \multicolumn{2}{|c|}{$95 \%$ confidence interval for mean } & \multirow[b]{2}{*}{ Minimum } & \multirow[b]{2}{*}{ Maximum } \\
\hline & & & & & Lower bound & Upper bound & & \\
\hline \multirow[t]{4}{*}{ Elite HD+ } & Control & 20 & 0.52035 & 0.003117 & 0.51889 & 0.52181 & 0.515 & 0.526 \\
\hline & UV radiation & 20 & 0.52910 & 0.001334 & 0.52848 & 0.52972 & 0.527 & 0.531 \\
\hline & Chemical & 20 & 0.54010 & 0.001917 & 0.53920 & 0.54100 & 0.537 & 0.544 \\
\hline & Total & 60 & 0.52985 & 0.008443 & 0.52767 & 0.53203 & 0.515 & 0.544 \\
\hline \multirow[t]{4}{*}{ Aquasil } & Control & 20 & 0.26745 & 0.002685 & 0.26619 & 0.26871 & 0.263 & 0.271 \\
\hline & UV radiation & 20 & 0.28245 & 0.002625 & 0.28122 & 0.28368 & 0.279 & 0.287 \\
\hline & Chemical & 20 & 0.29180 & 0.002285 & 0.29073 & 0.29287 & 0.289 & 0.295 \\
\hline & Total & 60 & 0.28057 & 0.010417 & 0.27788 & 0.28326 & 0.263 & 0.295 \\
\hline
\end{tabular}

Table 2: Comparison of the peel bond strength based on groups

\begin{tabular}{|c|c|c|c|c|c|c|c|}
\hline & & \multirow[b]{2}{*}{ Materials } & & \multirow[b]{2}{*}{ Mean difference (I-J) } & \multirow[b]{2}{*}{ Sig. } & \multicolumn{2}{|c|}{ 95\% confidence interval } \\
\hline & & & & & & Lower bound & Upper bound \\
\hline \multirow[t]{6}{*}{ Elite HD+ } & Tukey HSD & Control & UV radiation & -0.008750 & 0.000 & -0.01046 & -0.00704 \\
\hline & & & Chemical & -0.019750 & 0.000 & -0.02146 & -0.01804 \\
\hline & & UV radiation & Control & 0.008750 & 0.000 & 0.00704 & 0.01046 \\
\hline & & & Chemical & -0.011000 & 0.000 & -0.01271 & -0.00929 \\
\hline & & Chemical & Control & 0.019750 & 0.000 & 0.01804 & 0.02146 \\
\hline & & & UV radiation & 0.011000 & 0.000 & 0.00929 & 0.01271 \\
\hline \multirow[t]{6}{*}{ Aquasil } & Tukey HSD & Control & UV radiation & -0.015000 & 0.000 & -0.01693 & -0.01307 \\
\hline & & & Chemical & -0.024350 & 0.000 & -0.02628 & -0.02242 \\
\hline & & UV radiation & Control & 0.015000 & 0.000 & 0.01307 & 0.01693 \\
\hline & & & Chemical & -0.009350 & 0.000 & -0.01128 & -0.00742 \\
\hline & & Chemical & Control & 0.024350 & 0.000 & 0.02242 & 0.02628 \\
\hline & & & UV radiation & 0.009350 & 0.000 & 0.00742 & 0.01128 \\
\hline
\end{tabular}

in the surface roughness values was statistically significant at 0.00 level ( $p<0.05$ ) (Table 2). In general, the control groups (group la and group lla) presented the lowest surface roughness values and the chemical group (group Ic and group IIc) presented the highest surface roughness values.

\section{Discussion}

This null hypothesis was rejected as there was a statistically significant difference in the surface roughness of the polyvinylsiloxane elastomers when subjected to chemical disinfection and ultraviolet irradiation. Generally, dental impressions are disinfected by immersing them in an appropriate disinfectant solution or by spraying. Spraying leads to pooling of the disinfectant solution and hence not effective in disinfection. Hence, the immersion method was used in this study. Previous studies have demonstrated that polyvinylsiloxane impressions can be effectively disinfected on immersion with $2 \%$ glutaraldehyde for 10 minutes. Glutaraldehyde acts by fixation of the cell membrane and blocking the release of cellular components, thus killing the microorganisms. $^{3}$

Ultraviolet irradiation has shown to be an effective method of inactivating the microorganisms while preserving the quality of material. Ultraviolet light results in the formation of thymine-containing photoproducts in the DNA of affected cells. Studies have shown that the UV chamber can be safely used for the disinfection of the polyvinylsiloxane impression material without affecting its dimensional stability. ${ }^{10,11}$ The disinfection procedure can result in change in the properties of the material leading to changes in the surface roughness. Several studies have evaluated the surface roughness of gypsum casts ${ }^{8,9,12}$ obtained from elastomeric impressions. Studies on the measurement of surface roughness directly on the impressions are inadequate.

A significant difference in the surface roughness was observed within the control group for the two materials. The Elite $\mathrm{HD}^{+}$ specimens showed higher surface roughness values compared to the Aquasil specimens, which may be due to differences in the chemical composition in addition to the size, shape, and amount of the filler particles. Both the chemically disinfected and ultraviolet irradiated groups showed increased surface roughness values; however, greater increase was found for the chemically disinfected groups.

Since studies on the evaluation of surface roughness of polyvinylsiloxane impressions are limited, direct comparisons with the results obtained in this study cannot be made. Since chemical disinfection has limited success, ultraviolet radiation may be considered as an alternative to sterilize elastomeric impressions. However, before arriving at definite conclusion regarding the surface roughness, further research involving greater sample sizes is necessary.

\section{Conclusion}

Ultraviolet irradiation sterilization of polyvinylsiloxane elastomeric impressions could be considered an effective 
method compared to chemical disinfection since chemical disinfection results in a rougher impression surface. Among the two materials, Aquasil showed lower surface roughness compared to Elite $\mathrm{HD}^{+}$.

\section{References}

1. Walker MP, Rondeau M, Petrie C, et al. Surface quality and longterm dimensional stability of current elastomeric impression materials after disinfection. J Prosthodont 2007;16(5):343-351. DOI: 10.1111/j.1532-849X.2007.00206.x.

2. Olin PS, Holtan JR, Breitbach RS, et al. The effects of sterilization on addition silicone impressions in custom and stock metal trays. J Prosthet Dent 1994;71(6):625-630. DOI: 10.1016/00223913(94)90449-9.

3. Bhat VS, Shetty MS, Shenoy KK. Infection control in the prosthodontic laboratory. J Indian Prosthodont Soc 2007;7(2):62-65. DOI: 10.4103/0972-4052.33997.

4. Rohrer MD, Bulard RA. Microwave sterilization. J Am Dent Assoc 1985;110(2):194-198. DOI: 10.14219/jada.archive.1985.0250.

5. Holtan JR, Olin PS, Rudney JD. Dimensional stability of polyvinyl siloxane impression material following ethylene oxide and steam autoclave sterilization. J Prosthet Dent 1991;65(4):519-525. DOI: 10.1016/0022-3913(91)90292-5.
6. Naik RG, Dodamani AS, Vishwakarma P, et al. Assessment of efficacy of ultraviolet chamber in disinfecting dental instruments. J Pharm Heath Sci 2016;6:1586-1589.

7. Kowalski W, Bahnfleth W, Raguse M, et al. The cluster model of ultraviolet disinfection explains tailing kinetics. J Appl Microbiol 2019;128(4):1003-1014. DOI: 10.1111/jam.14527.

8. Adbullah MA. Surface detail, compressive strength, and dimensional accuracy of gypsum casts after repeated immersion in hypochlorite solution. J Prosthet Dent 2006;95(6):462-468. DOI: 10.1016/j. prosdent.2006.03.019.

9. Taylor RL, Wright PS, Maryan C. Disinfection procedures: Their effect on the dimensional accuracy and surface quality of irreversible hydrocolloid impression materials and gypsum casts. Dent Mater 2002;18(2):103-110. DOI: 10.1016/S0109-5641(01)00027-6.

10. Ishida $H$, Nahara $Y$, Tamamoto $M$, et al. The fungicidal effect of ultraviolet light on impression materials. J Prosthet Dent 1991;65(4):532-535. DOI: 10.1016/0022-3913(91)90295-8.

11. Godbole SR, Dahane TM, Patidar NA, et al. Evaluation of the effect of ultraviolet disinfection on dimensional stability of the polyvinyl silioxane impressions. An in vitro study. J Clin Diagn Res 2014;8:ZC73ZC76.

12. Rodriguez JM, Curtis RV, Bartlett DW. Surface roughness of impression materials and dental stones scanned by noncontacting laser profilometry. Dent Mater 2009;25(4):500-505. DOI: 10.1016/j. dental.2008.10.003. 